\title{
Could the implementation of a trauma checklist improve quality of care?
}

\author{
Elizabeth Ashton \\ From London Trauma Conference 2014 \\ London, UK. 9-12 December 2014
}

\section{Background}

Medical error in trauma care remains common [1]. Checklists are a cognitive aid that can be employed to standardise practice and minimise error. Their usage is ubiquitous in other high-intensity professions, such as aviation. Following the success of the World Health Organisation's surgical safety checklist they are now in the process of developing a trauma care checklist. My aim was to evaluate whether a checklist could be applied to the trauma setting to facilitate high quality, standardised care.

\section{Method}

1. Audit the prevalence of human factors during trauma calls in a major trauma centre in the UK

2. Literature review of the use of checklists in medicine

\section{Results}

- At least one incidence of negative human factors affecting trauma team performance was observed during each trauma call with the average incidence being three times per resuscitation.

- Evidence suggests that poor communication is the leading cause of medical error. This was corroborated by my audit findings.

- A review of literature shows that checklists in are effective tools for standardising care by reducing error and improving compliance with guidelines [2].

\section{Conclusion}

It is essential that organisational safety culture is addressed and the subject of human error is acknowledged to improve care provision and enhance patient safety. Checklists represent a promising method of tackling this issue

Correspondence: elizabeth.ashton@students.pcmd.ac.uk

Peninsula College of Medicine and Dentistry, Plymouth, UK that should be used synergistically with existing management strategies.

Published: 11 September 2015

References

1. Cooper DJ, McDermott FT, Cordner SM, Tremayne AB: "Quality assessment of the management of road traffic fatalities at a level I trauma center compared with other hospitals in Victoria, Australia. Consultatitive Committee on Road Traffic Fatalities in Victoria.". J Trauma 1998, 45(4):772-779.

2. Thomassen $\mathrm{O}$, et al: "The effects of safety checklists in medicine: a systematic review.". Acta Anaesthesiol Scand 2013, 58(1):5-18.

doi:10.1186/1757-7241-23-S2-A13

Cite this article as: Ashton: Could the implementation of a trauma checklist improve quality of care? Scandinavian Journal of Trauma, Resuscitation and Emergency Medicine 2015 23(Suppl 2):A13.
Submit your next manuscript to BioMed Central and take full advantage of:

- Convenient online submission

- Thorough peer review

- No space constraints or color figure charges

- Immediate publication on acceptance

- Inclusion in PubMed, CAS, Scopus and Google Scholar

- Research which is freely available for redistribution
C Biomed Central 